\title{
Reducing HIV risk for adolescent girls and young women and their male partners: Insights from the DREAMS Partnership
}

Sanyukta Mathur

Population Council

Follow this and additional works at: https://knowledgecommons.popcouncil.org/departments_sbsr-hiv How does access to this work benefit you? Let us know!

\section{Recommended Citation}

Mathur, Sanyukta. 2020. "Reducing HIV risk for adolescent girls and young women and their male partners: Insights from the DREAMS Partnership," presentation at "HIV Prevention programs among adolescent girls and young women (AGYW): Harmonised approaches to implementation and the way forward," Geneva, Switzerland, 30 January. 


\section{DOPULATION COUNCIL}

Ideas. Evidence. Impact.

\section{REDUCING HIV RISK FOR} ADOLESCENT GIRLS AND YOUNG WOMEN \& THEIR MALE PARTNERS

Insights from the DREAMS Partnership

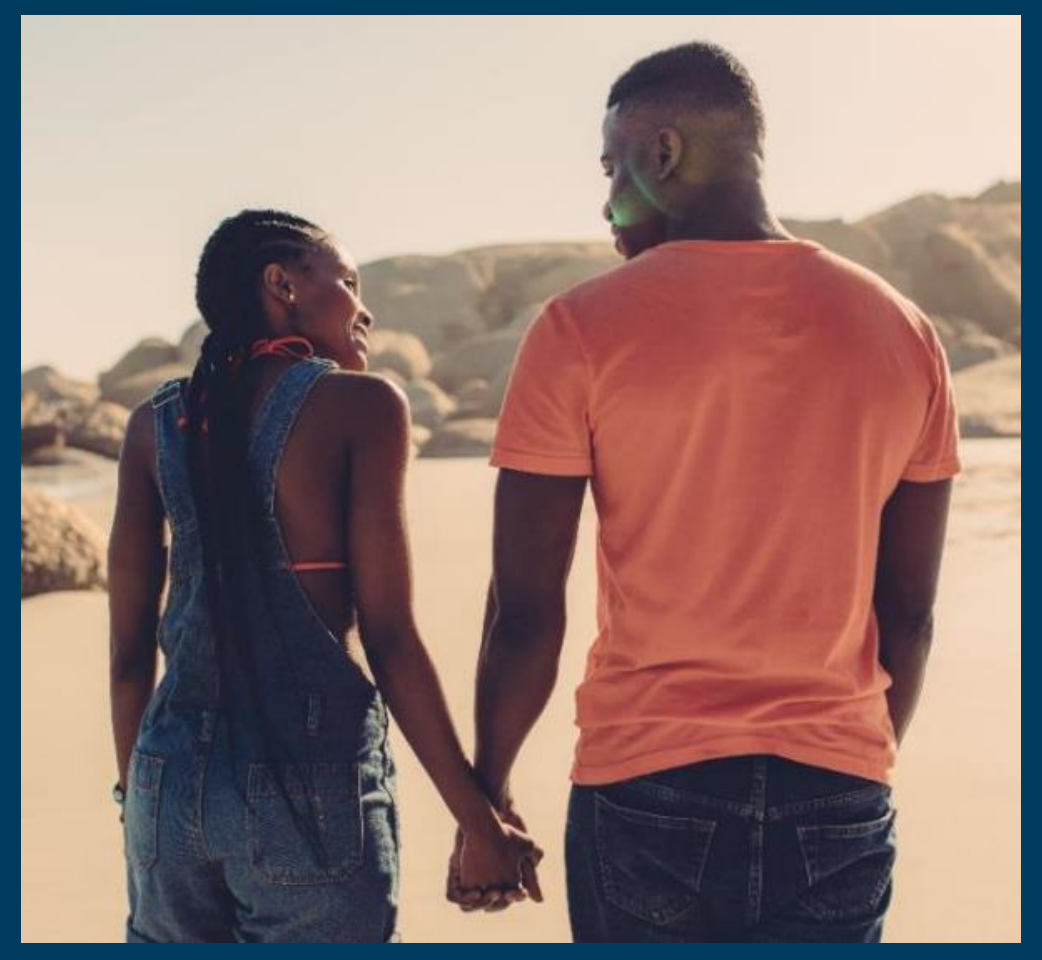

Sanyukta Mathur, DrPH MHS HIV Prevention programs among AGYW, UNAIDS 30 January 2020 smathur@popcouncil.org 


\section{DREAMS Implementation Science Research}

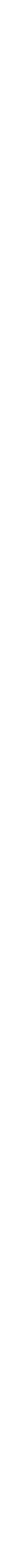




\section{Study sites \& data}

\begin{tabular}{|c|c|c|c|c|c|c|c|}
\hline & Kenya & Tanzania & Zambia & Malawi & Eswatini & $\begin{array}{l}\text { South } \\
\text { Africa }\end{array}$ & Uganda \\
\hline Quantitative & $\begin{array}{l}\text { DREAMS/ } \\
\text { non-DREAMS } \\
\text { AGYW } \\
\mathrm{N}=1,778 \\
\text { Panel data } \\
\text { DREAMS } \\
\text { AGYW } \mathrm{n}=740\end{array}$ & $\begin{array}{l}\text { Health provider } \\
\text { survey } n=361\end{array}$ & $\begin{array}{l}\text { DREAMS/ } \\
\text { non-DREAMS } \\
\text { AGYW } \\
\mathrm{N}=1,915 \\
\text { Panel data } \\
\text { DREAMS AGYW } \\
\mathrm{n}=885\end{array}$ & $\begin{array}{l}\text { Round } 1 \\
\text { DREAMS } \\
\text { AGYW } \\
n=1672 \\
\text { Panel data } \\
\text { DREAMS } \\
\text { AGYW } \\
n=1257 \\
\text { Men/MP of } \\
\text { AGYW } n=612\end{array}$ & $\begin{array}{l}\text { Men in 'hot } \\
\text { spots' } \\
\text { Round } 1 \\
\text { (MEASURE } \\
\text { Evaluation) } \\
n=843 \\
\text { Round } 2 \\
n=1,180\end{array}$ & $\begin{array}{l}\begin{array}{l}\text { Men in } \\
\text { informal } \\
\text { settlements }\end{array} \\
\text { Round } 1 \\
\mathrm{n}=962 \\
\text { Round } 2 \\
\mathrm{n}=886\end{array}$ & \\
\hline Qualitative & $\begin{array}{l}\text { DREAMS } \\
\text { beneficiaries } \\
n=27 \\
\text { Program staff } \\
n=27 \text { IDIs }\end{array}$ & $\begin{array}{l}\text { FSWs n=24 } \\
\text { Unmarried } \\
\text { AGYW 4 FGDs } \\
\text { Policymakers } \\
\text { n=21 IDIs } \\
\text { Parents / } \\
\text { guardians n=4 } \\
\text { FGDs } \\
\text { Partners of } \\
\text { AGYW n=16 IDIs }\end{array}$ & $\begin{array}{l}\text { DREAMS } \\
\text { beneficiaries } \\
\mathrm{n}=44 \\
\text { Program staff } \\
\mathrm{n}=31 \mathrm{IDIs}\end{array}$ & $\begin{array}{l}\begin{array}{l}\text { DREAMS } \\
\text { beneficiaries } \\
n=36 \text { IDIs }\end{array} \\
\text { Program staff } \\
n=35 \text { IDIs } \\
\text { Facilitators } \\
n=18 \text { FGDs } \\
\text { Men living } \\
\text { with HIV } n=4 \\
\text { FGDs \& } 16 \text { IDI }\end{array}$ & $\begin{array}{l}\text { MP of AGYW } \\
n=66 \text { IDIs } \\
\text { Program staff } \\
n=3 \text { FGDs }\end{array}$ & $\begin{array}{l}\text { MP of AGYW } \\
n=72 \text { IDIs } \\
\text { Program staff } \\
n=3 \text { FGDs }\end{array}$ & $\begin{array}{l}\text { MP of AGYW } \\
n=126 \text { IDIs } \\
\text { Program staff } \\
n=9 F G D s\end{array}$ \\
\hline
\end{tabular}




\section{How can we better understand HIV vulnerability/risk \& tailor programming?}




\section{Even in these contexts, differences in vulnerability (among out-of-school AGYW)}
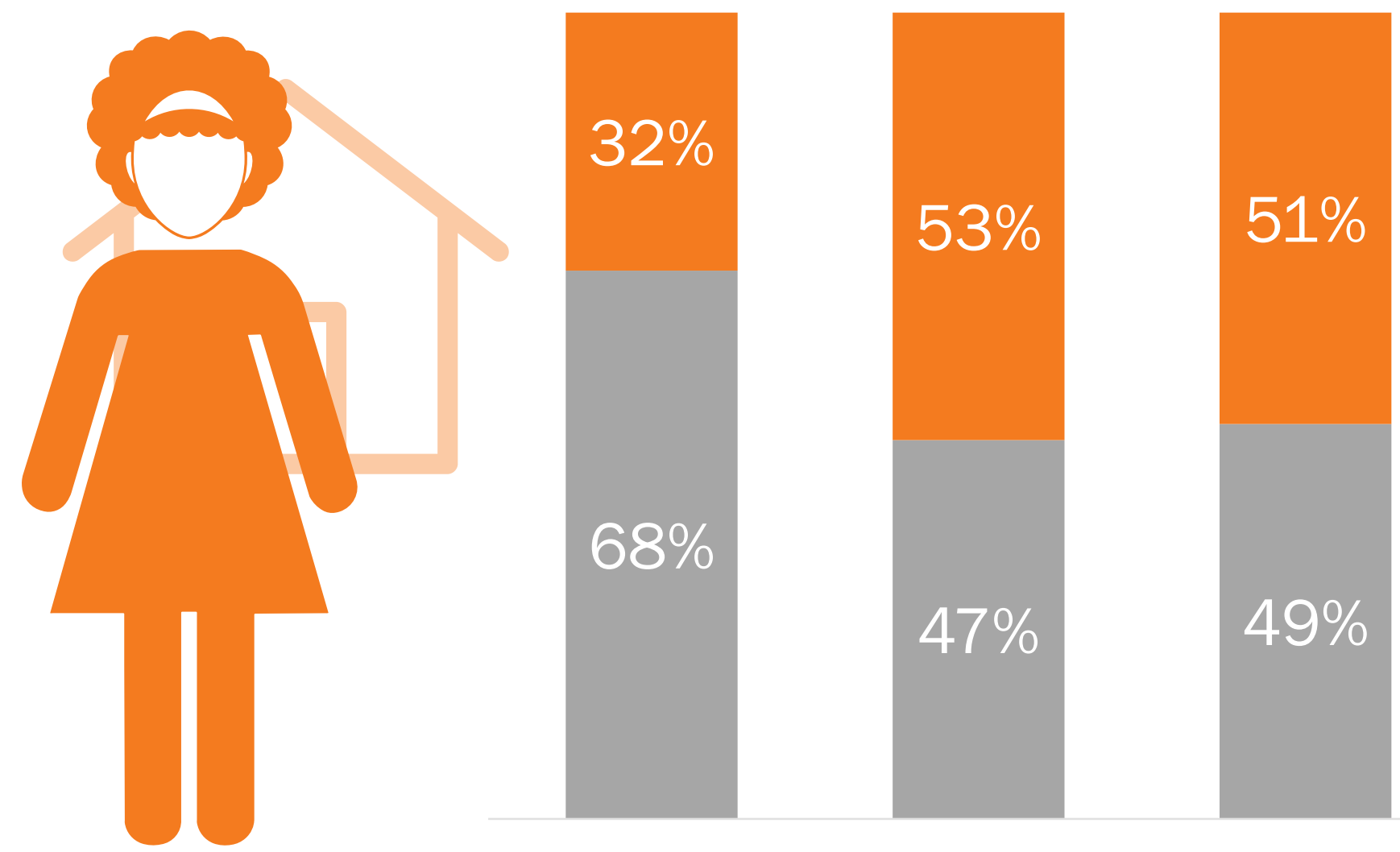

\section{Higher HIV vulnerability}

$$
\begin{array}{ccc}
\text { Kenya } & \text { Malawi } & \text { Zambia } \\
(n=1,014) & (n=1,652) & (n=846)
\end{array}
$$




\section{Multiple characteristics define high HIV vulnerability}

\begin{tabular}{|lccc|}
\hline & Kenya & Malawi & Zambia \\
\hline Moderate HH wealth & $\checkmark$ & $\checkmark$ & $\checkmark$ \\
Lack of adult supervision & $\checkmark$ & $\checkmark$ & $\checkmark$ \\
Sometimes or often hungry & $\checkmark$ & & $\checkmark$ \\
No comprehensive knowledge of HIV & $\checkmark$ & $\checkmark$ & $\checkmark$ \\
No comprehensive knowledge of condoms & & $\checkmark$ \\
\hline Lower support for equitable gender norms & $\checkmark$ & & \\
\hline
\end{tabular}




\section{Distinct subgroups of men found, who should be targeted differently with programming}

- Not just older high-risk men, younger men have high HIV risk profiles too.

- Risk profiles of older and younger men don't look the same.

- Distinguishing variables include type of employment, alcohol use, gender attitudes, number of partners.
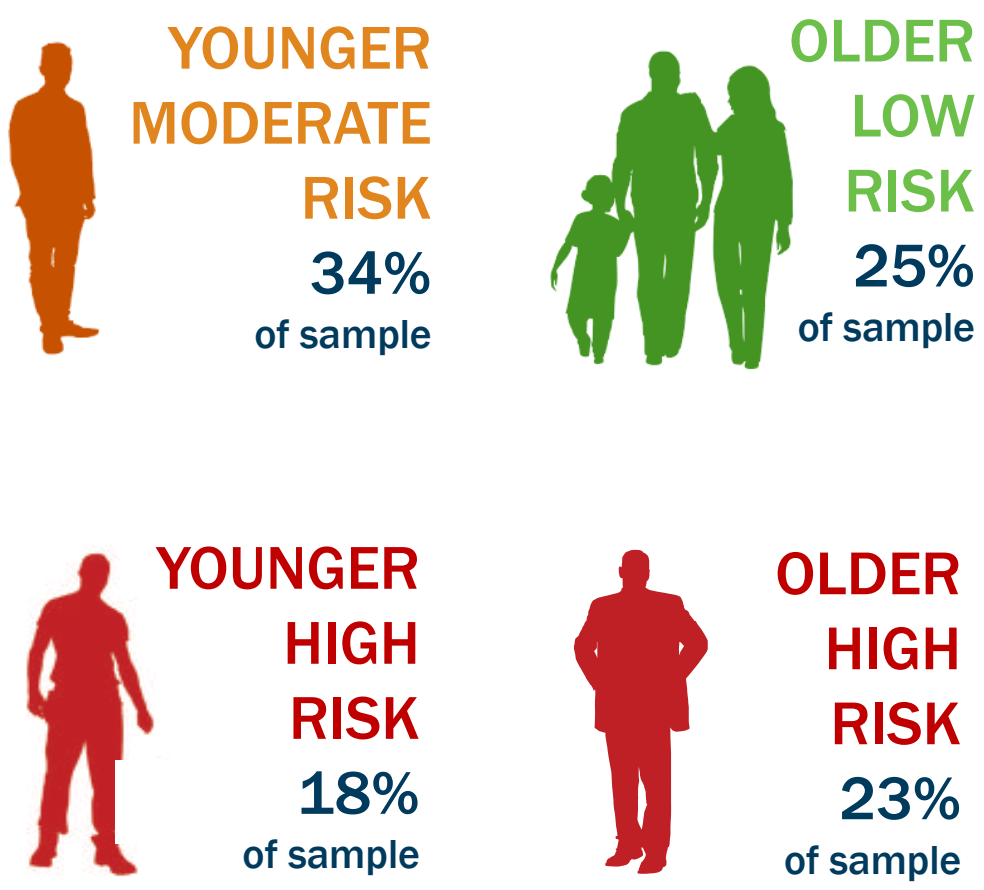

OLDER HIGH RISK $23 \%$ of sample 
What are the effects of DREAMS' multi-sectoral, community-based approach to HIV prevention? 
Adolescent girls, program exposure $(n=380)$

Relatively

high exposure

to DREAMS

interventions
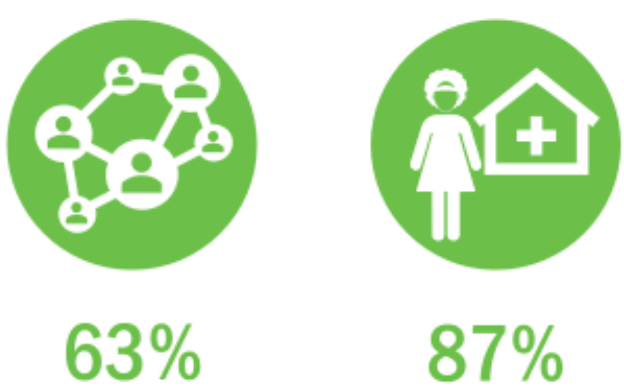

Social asset building

completion

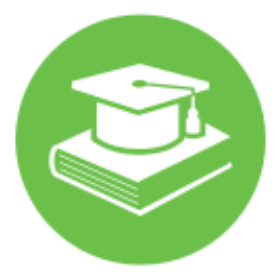

$49 \%$

Educational social

protection

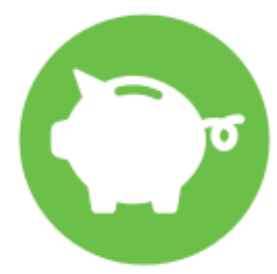

$33 \%$

Economic social

protection

Young women, program exposure $(n=505)$

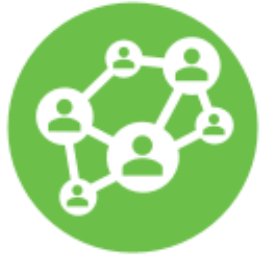

$58 \%$

Social asset building completion

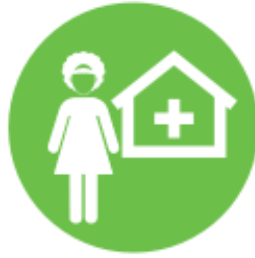

$78 \%$

Youth-friendly SRH services offered
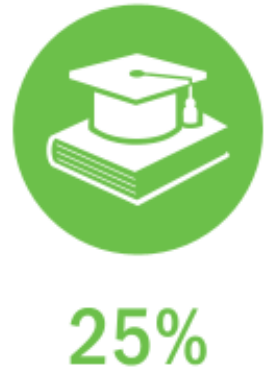

Educational social protection

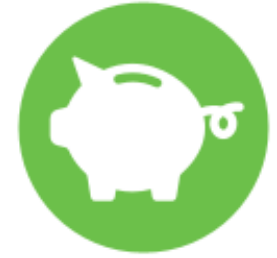

$27 \%$

Economic social protection 


\section{Very positive DREAMS experiences}

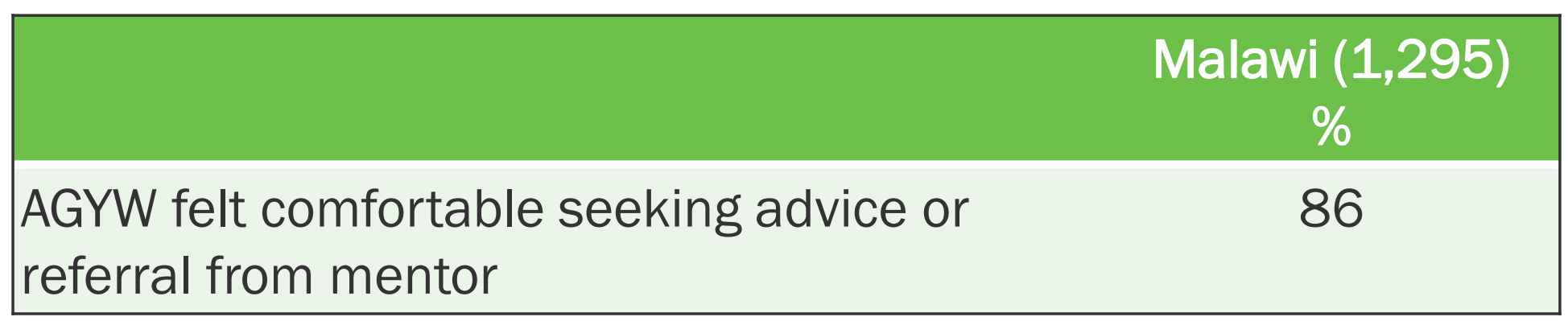

Now that I am aware of these issues surrounding the HIV virus and how it can be contracted or avoided that is why I stopped my old way of putting my life at risk because of my participation in the club....

-23 yr old, Zomba, Malawi 
Male partners of AGYW benefited from interventions that addressed social and gender norms

- Men noted improved couple communication and conflict resolution, reduction, or elimination inside partners, and greater impetus to link to HIV services.

[My partner and I] now know how to communicate with each other...we no longer have arguments over simple things....

-Male partner, Mukono
The meeting taught me, as a person, to be safe, and practice self-control.... Have one partner [and] stop admiring other women....

-Male partner, Sembabule 


\section{Change over time among DREAMS beneficiaries}

- Significant improvements in HIV knowledge, self-efficacy, \& HIV testing.

- Lower physical and sexual violence from partners and non-partners over time.

- No significant reductions in sexual risk behaviors (e.g. 2+ partners)

- Some reductions in condom use and increase in transactional sex (w/ casual partner) 


\section{Changes in sexual behaviors among 15-24 yr olds over time}

\section{ZAMBIA $(\mathrm{N}=\mathbf{8 8 5})$}

\author{
- 2016-2017 घ2018
}

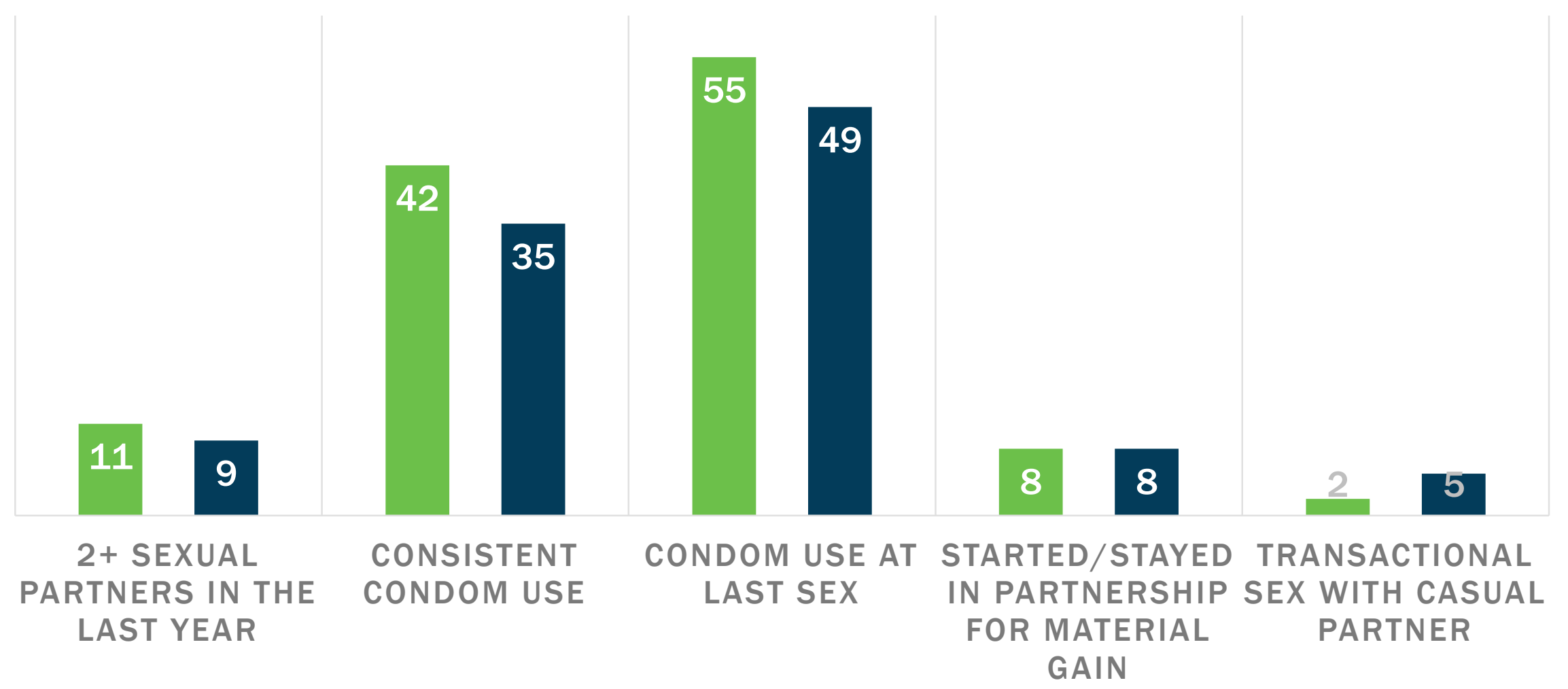




\section{Yet, condom use higher among adolescents who received programming}

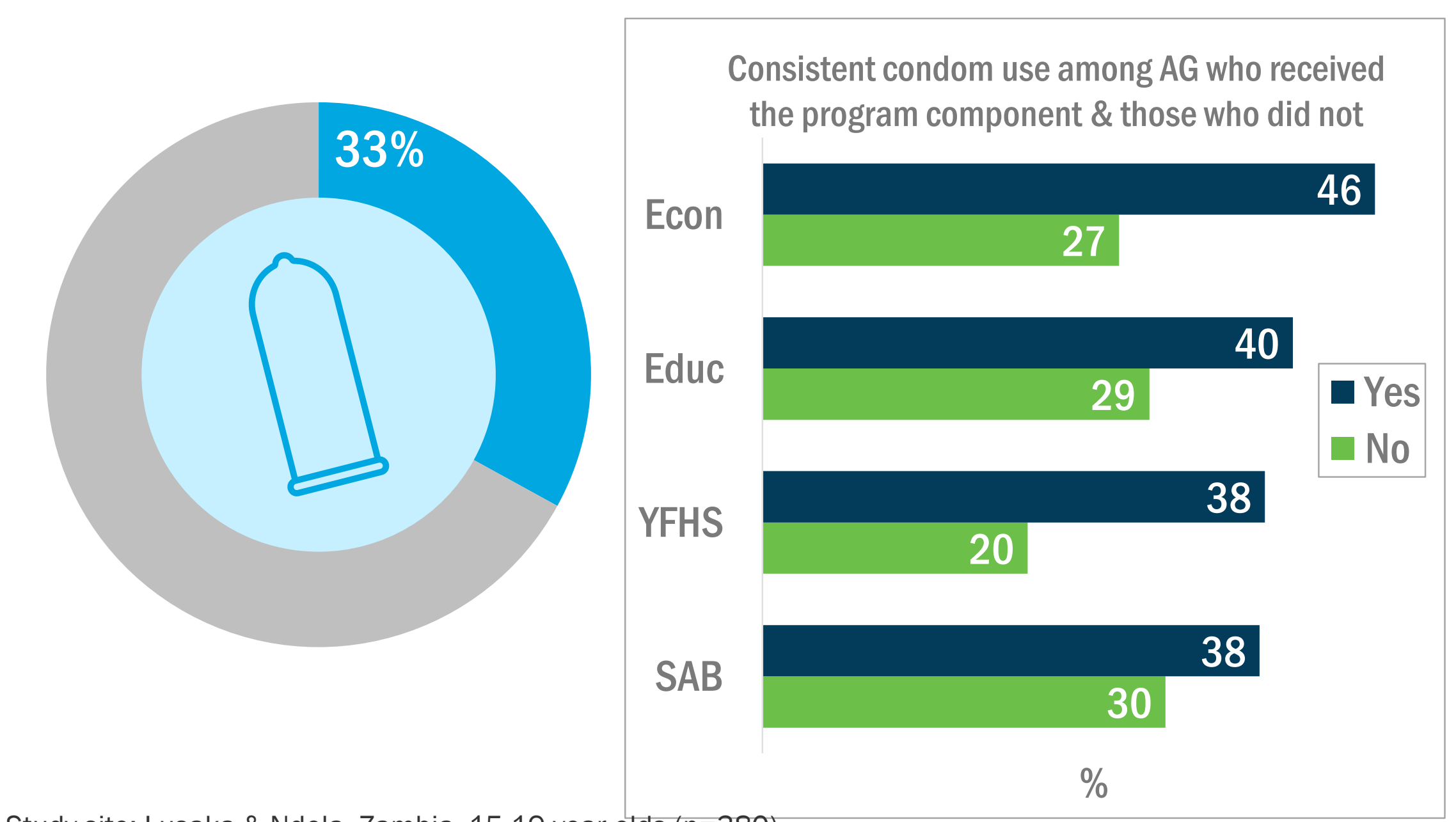

Study site: Lusaka \& Ndola, Zambia, 15-19 year olds $(n=380)$ 


\section{And, transactional sex lower among adolescents who received programming}



Study site: Lusaka \& Ndola, Zambia, 15-19 year olds $(n=380)$ 


\section{What is the influence of "layered" DREAMS programming on HIV-related outcomes?}




\section{New analytical technique identifies how program exposure predicts an outcome}

- Classification and Regression Tree (CART) analysis

- Explores the relationships between program components and select outcomes

- Uses a recursive partitioning method for predicting dependent variables (regression) and categorical predictor variables (classification)

- Allows for interactions among predictor variables

- Provides the importance of each variable included into the algorithm in predicting the target variable 


\section{What pathways reduced likelihood of transactional sex among 15-19 year olds?}

1. AG who completed the social asset building curriculum \& received educational support.

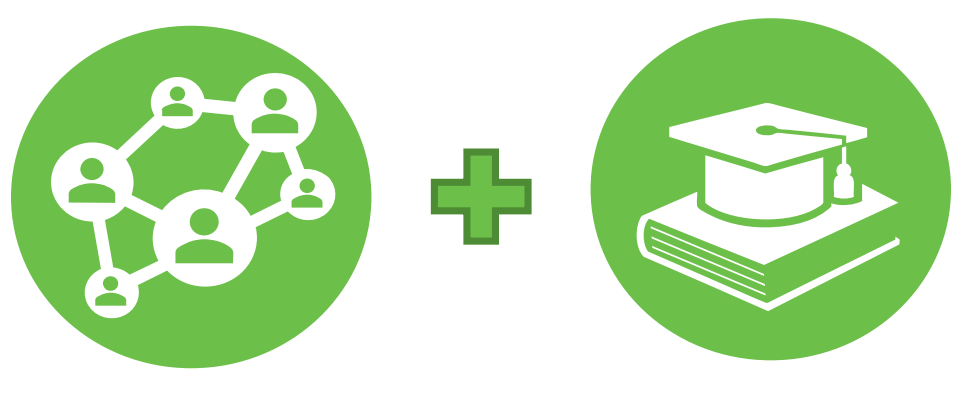

2. For those AG who did not complete social asset building curriculum, those who received economic support.

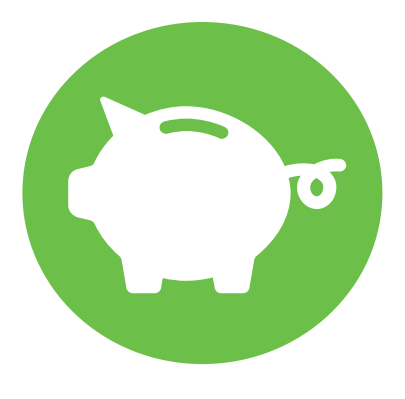




\section{What pathways reduce likelihood of transactional sex among 20-24 year olds?}

1. Completion of social asset building curriculum, receiving YFHS, and educational support, if no economic

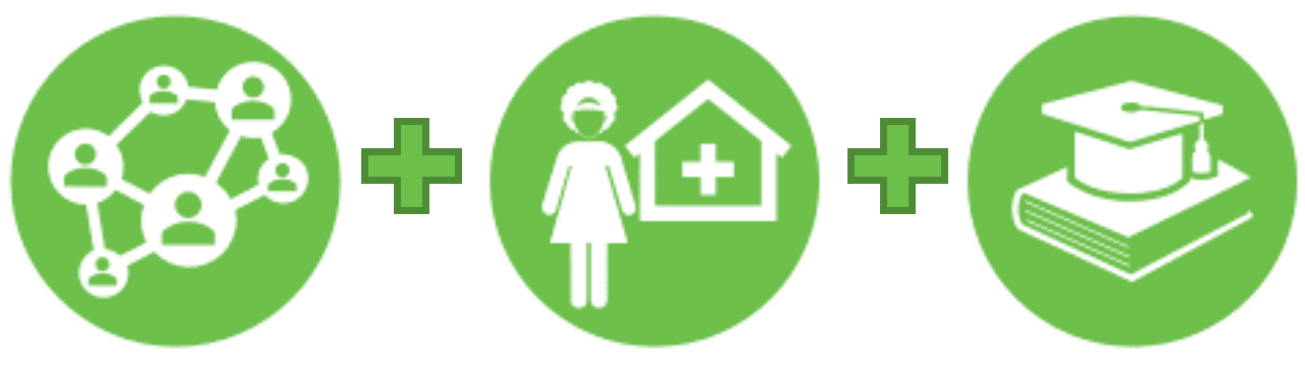
support.

2. Economic support \& educational, but did not complete social asset building curriculum.






\section{Pathways to increase the likelihood of consistent condom use?}

- Increased from $33 \%$ to $57 \%$ among 15-19 year olds who received economic support, completed social asset building curriculum \&

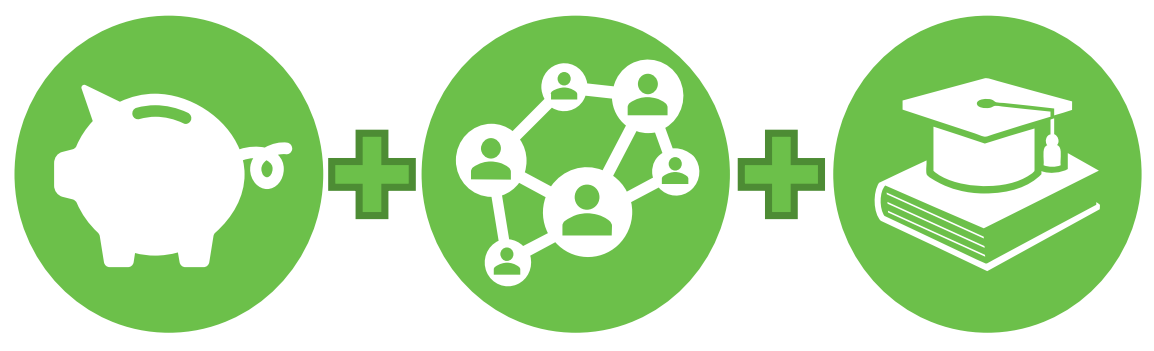
received educational support.

- Increased from $36 \%$ to $60 \%$ among 20-24 year olds who received economic support. 
What are we learning about effect of layering?

Different combinations of program components influence HIV related outcomes for adolescent girls than for young women

- For AG in urban Zambia, social asset building and educational support are more consistently important.

- For YW urban Zambia, YFHS, education and economic support more consistently important. 
How should we shift programming in the future? 


\section{Consider perceived benefits of AG vs. YW program participants}

- AG were more receptive to building social networks and gaining knowledge.

- YW were keen to access skills, training, and tangible resources or options to enhance their livelihood skills.

In my opinion, I feel that for the people to be motivated we should be provided with money to start a business so that the profits can be deposited in a VSL they advised that we should establish. At the moment the people are demotivated ...and we don't know ways which we can encourage them...so in my opinion what is needed is money to established businesses.

- DREAMS Implementing Partner, Malawi 


\section{Introducing PrEP for AGYW requires multi-level considerations}

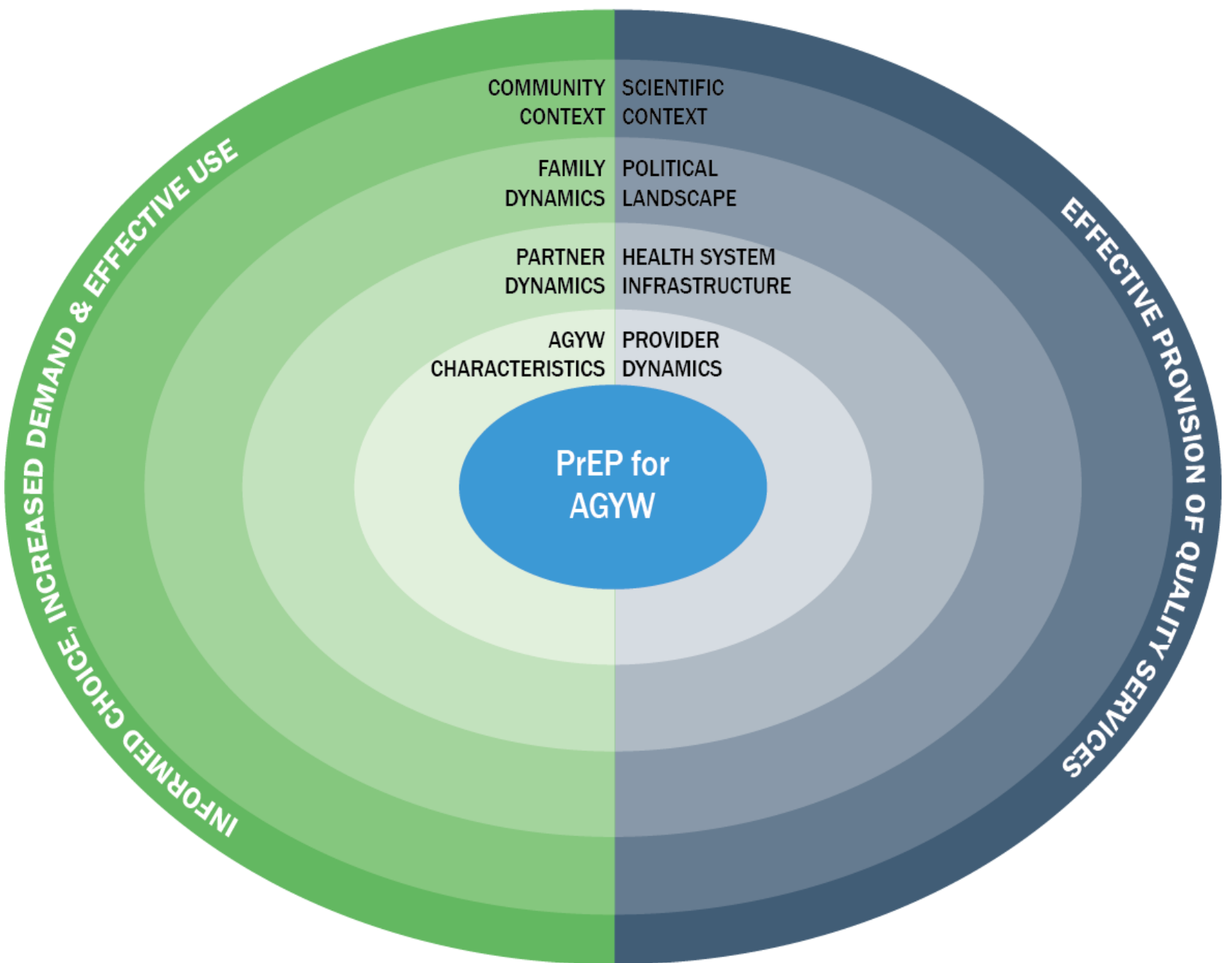




\section{Address PrEP-related stigma \& provide AGYW with strategies to support effective use}

When the peers of my age see a person taking PrEP, they will think that the person has AIDS or they are very unfaithful hanging out with many partners. They will speak many things and I will be considered as a bad person in the community, a misbehaving person.

\section{-AGYW, age 22, Tanzania}

- AGYW want:

- Accurate information about side effects.

- Peer support groups (in-person or virtual), reminders via calls/SMS.

- Education of partners and parents.

- Skills to assess HIV risk during key life transitions. 


\section{How to tailor to reach men at highest HIV risk}

- Vigilant testers: perceived importance of early treatment

I didn't decide [to test], I met people like you doing door to door testing so I just used that chance and tested. (Siphofaneni, age 31)

- Willing yet non-proactive testers: most common

...it is wiser to know your status and hence take your ARVs before the sickness weakens your immune system to near death, causing...people to gossip about you. (Matsapha, age 34)

- Resistant testers: smallest group, yet also highest risk

...testing has to come from my heart before taking that decision.... I don't want to take the decision yet in the end that thing will haunt me. ... have never tested.... (Matsapha, age 23) 


\section{Implementers need new systems of communication, coordination, and management across organizations}

At the beginning everyone was trying to figure out how you put the pieces together. Everyone was running with their own targets, but I think even at the community level, there were different partners implementing DREAMS, so sometimes the schools were confused....

- DREAMS Implementer, management staff, Zambia 


\section{Implementing partners need capacity strengthening}

- Tools to map AGYW in program community, and assess community resources that AGYW have access to

- Identify male partners of AGYW

- Tools to strengthen skills/capacities of program mentors

- Training and partnerships to strengthen non-health components of the program

- Monitoring program implementation

- Use of program data to assess program effects 


\section{Girl Roster ${ }^{\mathrm{TM}}$ Tool}

- Brief questionnaire administered via Android phones by program staff using nonsensitive questions in 7-10 minutes.

- User-friendly, easy to implement program design.

- Lays foundation for targeted, evidence-based girl-centered program design decisions.

\begin{tabular}{|c|c|c|c|c|c|c|c|}
\hline \multirow[b]{3}{*}{$\begin{array}{l}\text { Age } \\
\text { Group }\end{array}$} & \multicolumn{4}{|c|}{ Unmarried } & \multicolumn{2}{|c|}{ Married } & \multirow[b]{3}{*}{ Total } \\
\hline & \multicolumn{2}{|c|}{ In School } & \multicolumn{2}{|c|}{ Out of School } & \multirow[b]{2}{*}{$\begin{array}{l}\text { Has A } \\
\text { Child }\end{array}$} & \multirow[b]{2}{*}{$\begin{array}{c}\text { Does Not } \\
\text { Have A } \\
\text { Child }\end{array}$} & \\
\hline & $\begin{array}{c}\text { Living } \\
\text { with both } \\
\text { parents }\end{array}$ & $\begin{array}{l}\text { Living with } \\
\text { just one } \\
\text { or neither } \\
\text { parent }\end{array}$ & $\begin{array}{c}\text { Living } \\
\text { with both } \\
\text { parents }\end{array}$ & $\begin{array}{c}\text { Living } \\
\text { with just } \\
\text { one or } \\
\text { neither } \\
\text { parent }\end{array}$ & & & \\
\hline 06-09 & 62 & 7 & 55 & 15 & - & - & 139 \\
\hline $10-14$ & 60 & 10 & 22 & 11 & 1 & 9 & 113 \\
\hline \multirow[t]{2}{*}{$15-17$} & 19 & 1 & 3 & 2 & 9 & 5 & 39 \\
\hline & & & & & & & 291 \\
\hline
\end{tabular}

291 girls 6-17 were identified in 278 households. Nearly half "off-track." 


\section{Content to strengthen AGYW programming for DREAMS program partners-Building Assets Toolkit $^{\odot}$}

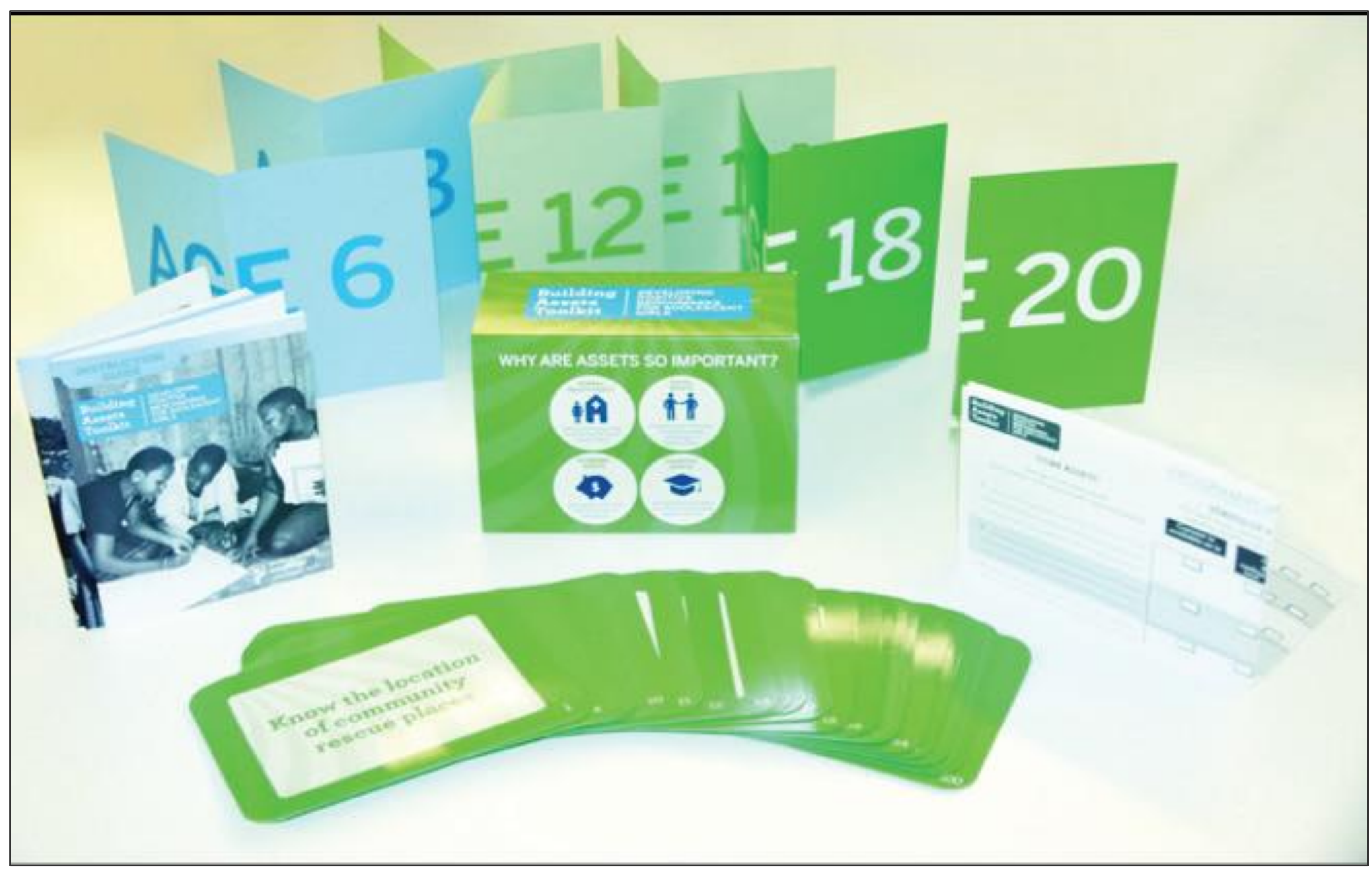




\section{Stay tuned...}

- Understanding reasons for PrEP discontinuation among young female sex workers

- Assessing program effects of DREAMS among most atrisk AGYW

- Multi-country perspectives on men living with HIV and their engagement with the treatment cascade

- Intersections of financial agency, gender dynamics, and HIV risk

- Upcoming special issues

- Stigma (AIDS)

- Evidence to meet the 90-90-90 goals (PLOS Collection) 


\section{Acknowledgements}

- Population Council: Sanyukta Mathur, Ann Gottert, Julie Pulerwitz, Miriam Temin, Jerry Okal, Maurice Musheke, Nanlesta Pilgrim, Nrupa Jani, Craig Heck, Sangram K. Patel, Bidhubhushan Mahapatra, Monika Walia, Louis Apicella, Mike Mbizvo, James Matheka, Drosin Mulenga, Lyson Tethani, John Mark Wiginton, Cristian Valenzuela, Pamela Keilig

- Kenya \& Zambia: Collaboration with DREAMS Implementing Partners (PATH/Aphia Plus, PACT) \& local USAID and PEPFAR DREAMS teams

- Malawi: Local implementing partner - COM, Effie Chipeta, Victor Mwapasa, Wanangwa Chimwaza \& Collaboration with USAID/Malawi and DREAMS IPS

- Tanzania: Local implementing partner-CSK (Catherine Kahabuka), Neema Makyao (NACP, Tanzania) \& collaboration with NACP/MOH and local USAID and PEPFAR DREAMS teams

- South Africa Local research partner-Epicentre: Cherie Cawood, \& collaboration with: South African DOH, SANAC, eThekwini Municipality, PEPFAR-South Africa, DREAMS Implementing Partners

- Eswatini: Local research partner \& investigators-Institute for Health Measurement (IHM): Patrick Shabangu, Kelvin Sikwibele, Muhle Dlamini (SNAP), Muziwethu Nkhambule (NERCHA); \& Collaboration with Ministry of Health, NERCHA, SNAP, PEPFAR-Eswatini, DREAMS Implementing Partners

- Uganda Local research partner-Makerere University, Child Health and Development Centre (CHDC): Godfrey Siu, Anne Katahoire, \& Collaboration with: Ministry of Health, District local government, PEPFAR-Uganda, DREAMS Implementing Partners 


\section{population Precosent}

Ideas. Evidence. Impact.






\section{POPULATION}

COUNCIL

Ideas. Evidence. Impact.

\section{EXTRA SLIDES}


What are some striking insights around social drivers of HIV risk among AGYW and their male partners? 


\section{Older AGYW have less power in their relationships than younger AGYW}

-15-17 years $\quad 18-20$ years $\square$ 21-24 years $(n=1,101)$

My partner has more say than I do about important decisions that affect us*

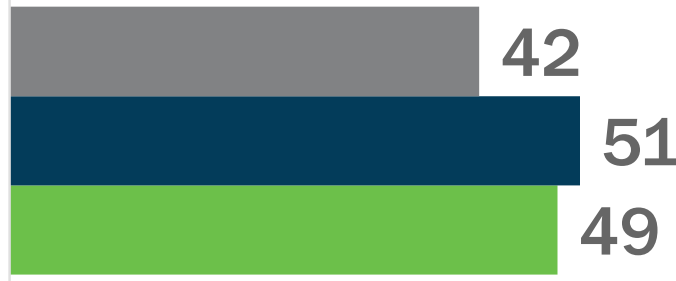

If my partner wants to have sex, he would expect me to agree*

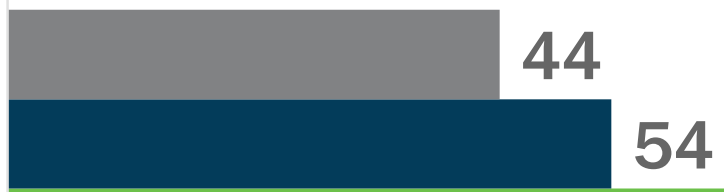

When my partner and I disagree, he gets his way most of the time*

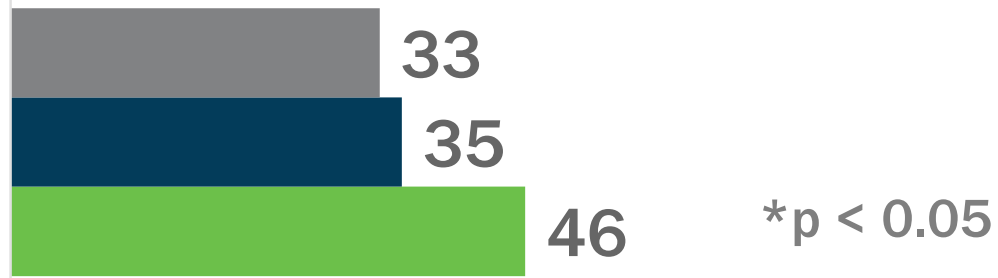

Study site: Kisumu County, Kenya

Pulerwitz J, Mathur S, Woznica D (2018) How empowered are girls/young women in their sexual relationships? Relationship power, 


\section{Relationships are often characterized by}

conflict, material transactions, transitions, and inequality

- Men described conflict and miscommunication as the primary motivation for seeking additional partners.

- Men saw money and gifts as the only way of establishing and maintaining relationships with women.

- Men view most young women as active agents in pursuing transactional sex for cash or material goods.

- Men intentionally sought young women because they are more compliant. 


\section{Men describe common trajectories for multiple partnerships}

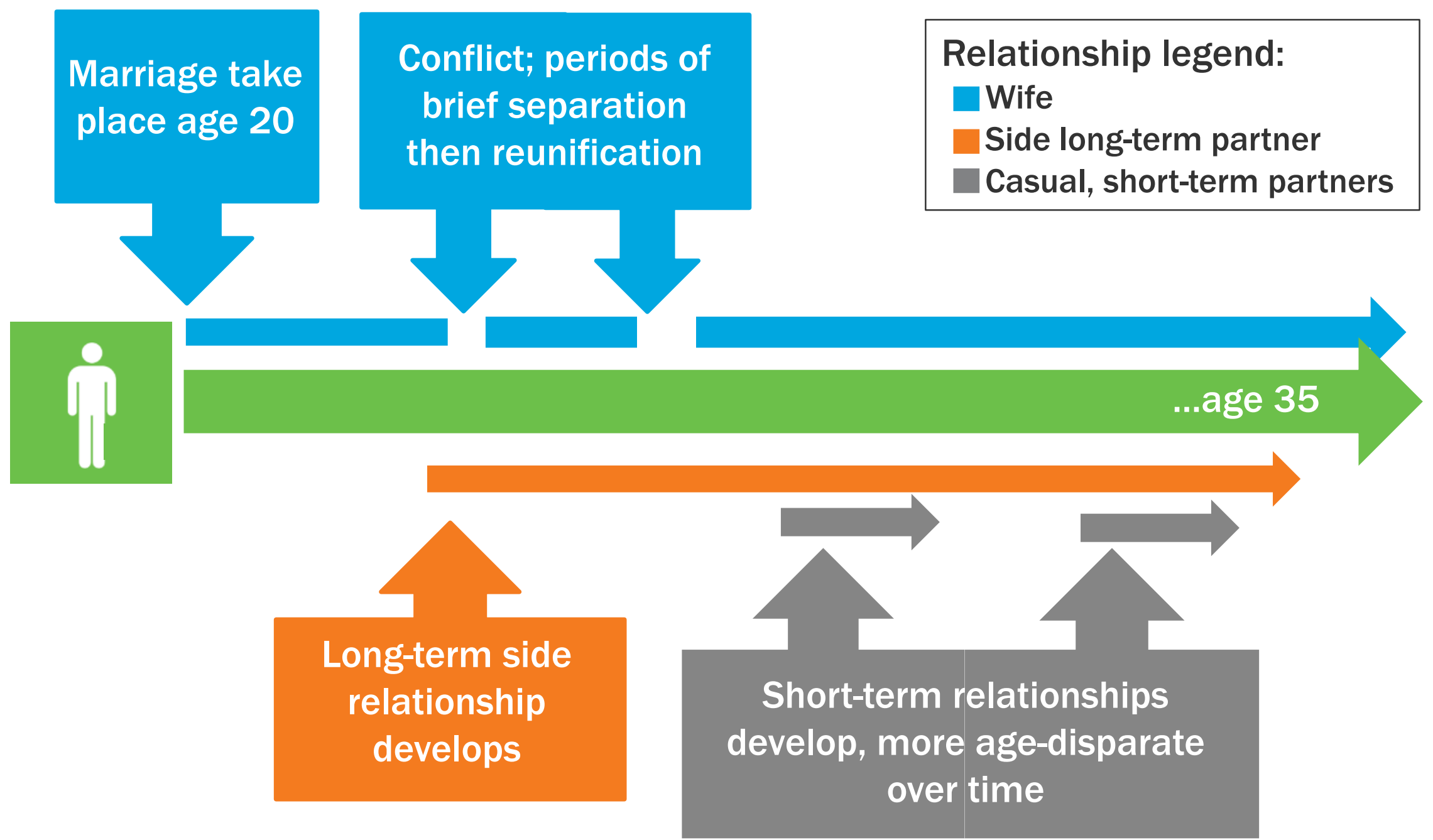

38 Study site: Uganda (94 IDIs) 


\section{Men's experiences with violence frequent, strongly associated with HIV risk behaviors}



In lifetime

Witnessed an armed attack

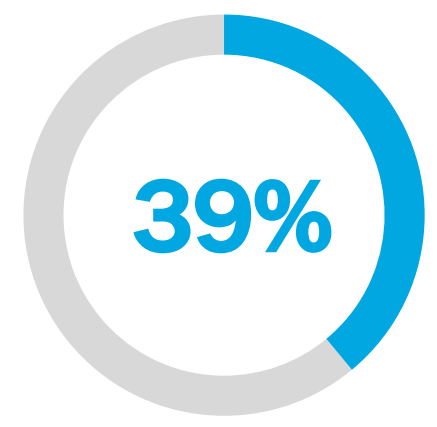

In lifetime

Robbed at

gunpoint of

knifepoint

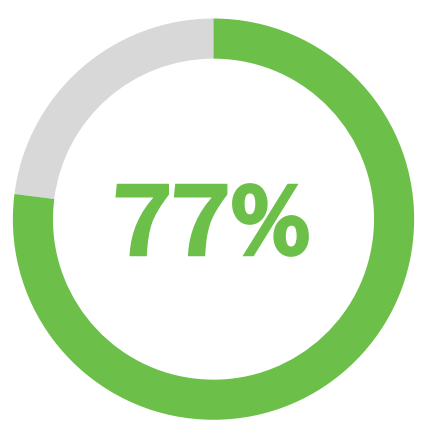

Before age 18

Beaten at home

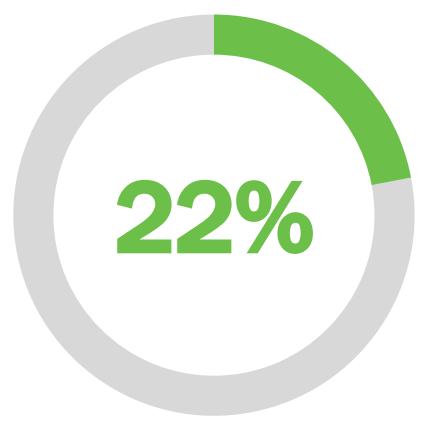

Before age 18 Saw/heard mother being beaten

- Lifetime experiences of violence associated with having multiple sexual partners in last year $(p=0.001)$.

- Childhood experiences of violence associated with having multiple sexual partners in the last year and inconsistent condom use (both $p<0.05$ ). 


\section{Stigma inhibits AGYW's access to and use of PrEP}

Factors associated with providers' willingness to prescribe PrEP $(n=316)$

\begin{tabular}{|lc|}
\hline & $\begin{array}{c}\text { Adj. IRR } \\
(95 \% \mathrm{Cl})\end{array}$ \\
\hline $\begin{array}{l}\text { Negative attitudes } \\
\text { toward AGYW } \\
\text { sexuality }\end{array}$ & 0.81 \\
$\begin{array}{l}\text { Behavioral } \\
\text { disinhibition scale }\end{array}$ & $(0.66-0.99)^{*}$ \\
\hline
\end{tabular}

${ }^{1}$ Adjusted for provider demographics, prior PrEP knowledge, other facility factors (e.g., stockouts) ${ }^{*} p<0.05$
- Parents, partners, health care providers, and policymakers agree that AGYW need PrEP due to sociocultural circumstances (e.g., violence, inability to refuse or negotiate safe sex) that increase their HIV risk.

- Yet have stigmatizing attitudes toward adolescent sexuality and concerns about an acceleration in risk behaviors due to PrEP availability. 